Research paper

\title{
Study on the mechanical properties of hydrate-bearing silty clay
}

\author{
X.H. Zhang ${ }^{\text {a, }}{ }^{\text {, X.B. Lu }}{ }^{\text {a, }}$, Y.H. Shi ${ }^{\text {b, } 2}$, Z. Xia ${ }^{\text {b, } 3}$ \\ ${ }^{a}$ Key Laboratory of Fluid-Solid Coupling System Mechanics, Institute of Mechanics, Chinese Academy of Sciences, Beijing, 100190, China \\ ${ }^{\mathrm{b}}$ Marine Environmental and Engineering Geological Survey, Guangzhou Marine Geological Survey, Guangzhou, 510075, China
}

\section{A R T I C L E I N F O}

\section{Article history:}

Received 23 August 2014

Received in revised form

15 April 2015

Accepted 28 April 2015

Available online 6 May 2015

\section{Keywords:}

Hydrate

Silty-clay

Secant modulus

Shear strength

The Drucker-Prager criterion

The mixed law

\begin{abstract}
A B S T R A C T
The mechanical properties are important for the evaluation of stratum deformation and instability in hydrate exploitation. By using an integrated test apparatus for synthesis of hydrate sediment and triaxial tests, a series of compression tests is conducted on the silty clay containing tetrahydrofuran hydrate (SCTH) similar to that of South China Sea. The stress-strain curves and Mohr circles are obtained at different degree of hydrate saturations and confining pressures. The silty clay containing tetrahydrofuran hydrate shows typical ductile behavior, the shear strength increases linearly with the increase of hydrate saturation and confining pressure. The secant modulus increases with the increase of hydrate saturation. The shear strength is analyzed based on the Drucker-Prager criterion, Mohr-Coulomb criterion, Lade -Duncan criterion, while the secant modulus is analyzed using the mixed law of composite materials. It is shown that the strength can be well described by the Drucker-Prager criterion and Mohr-Coulomb criterion, and the secant modulus is close to the harmonic average of the modulus of soil skeleton and hydrate in SCTH.
\end{abstract}

() 2015 Elsevier Ltd. All rights reserved.

\section{Introduction}

Hydrate, formed by methane, carbon dioxide, hydrogen sulfide, tetrahydrofuran and water molecules is a crystalline solid like ice under proper pressure and temperature. Natural gas hydrate is an important energy resource in the 21st century (Kvenvolden and Lorenson, 2001; Koh, 2002). Gas hydrate-bearing sediment (GHBS) has been sampled from many fields over the world such as Mallik in Canada (Numasawa et al., 2008), Alaska in America (ConocoPhillips, 2012), the northern continental slope in the South China Sea, Dongsha sea area and Qilian Mountains tundra in China.

Gas hydrate-bearing sediment is a mixture containing hydrate, soil/rock skeleton, water and gas. The mechanical properties of GHBS before and after hydrate dissociation are fundamental for soil response during hydrate exploitation and exploration.

The mechanical properties of GHBS are studied by tri-axial tests of artificial samples. The effects of hydrate occurrence mode, hydrate saturation, temperature, effective confining pressure on the

\footnotetext{
* Corresponding author. Tel.: +86 1082544192.

E-mail addresses: zhangxuhui@imech.ac.cn (X.H. Zhang), xblu@imech.ac.cn (X.B. Lu), yaohongshi@126.com (Y.H. Shi), xia-zhen@163.com (Z. Xia).

1 Tel.: +86 1082544190 .

2 Tel.: +86 2082251639 .

3 Tel.: +86 2082020437 .
}

modulus and the shear strength have been studied mainly by using hydrate-bearing sands (Clayton et al., 2005; Winters et al., 2004, 2007; Masui et al., 2007; Hyodo et al., 2007, 2014; Zhang et al., 2012; Li et al., 2012). The results indicate that the modulus and shear strength increase with the increase of effective confining pressure and hydrate saturation. Strain softening occurs when the hydrate saturation attains to $25 \%$. Hydrate occurrence modes, such as pore filling and cementation, affect the micro interaction of hydrate and soil grains. The mechanical properties of THF hydrate soil are also investigated (Yun et al., 2007), and the results indicate that the tangent stiffness of THF hydrate-bearing soil decreases with the increase of shearing.

The modified Cam-Clay model, Duncan-Chang model and damage model have been used to formulate the stress-strain relationship of GHBS. The Duncan-Chang model and damage model are applied to model ideally elastic-plastic behavior (Yu et al., 2011; Li et al., 2012) and strain softening (Wei et al., 2011), respectively. The modified Cam-Clay model can account for shearing and volumetric dilation of hydrate-bearing sands. However, its verification for hydrate-bearing silty-clay is required (Mayazaki et al., 2008, 2011a,b; Uchida et al., 2012; Dai et al., 2012). Although the relationships of the modulus and shear strength with hydrate saturation are well fitted, their physical meaning remained unclear (Birchwood et al., 2008). Hence, it seems reasonable to use different constitutive models to simulate different GHBS. 
In this paper, the mechanical properties of SCTH are investigated by tri-axial tests and theoretical analysis. Firstly, silty clay is used as the soil skeleton, THF hydrate is formed in the pores of soils at different degrees of hydrate saturation, which is similar to GHBS sampled from the South China Sea in hydrate saturation, dry density and grain size distribution. Secondly, the tri-axial tests are conducted under different effective confining pressures. Finally, the mechanical properties are formulated to provide practical references.

\section{Test illustration}

The tests are conducted using the integrated test apparatus for synthesis of hydrate sediment and tri-axial tests. The test setup is shown in Figure 1. The apparatus can provide an effective confining pressure ranging from 0 to $20 \mathrm{MPa}$ with an accuracy of $0.5 \%$ and a temperature from $-20{ }^{\circ} \mathrm{C}$ to $20{ }^{\circ} \mathrm{C}$ with an accuracy of $2.5 \%$. The maximum back-pressure is provided by a gas-supply cylinder as $10 \mathrm{MPa}$. Some detailed information about the apparatus is given by Zhang et al. (2012).

The grain size distribution of the silty-clay is shown in Figure 2. The specific gravity is about 2.7 , and the dry density is $1.3 \mathrm{~g} / \mathrm{cm}^{3}$ with a porosity of $52.1 \%$. So the pore volume of a specimen is $50 \mathrm{~cm}^{3}$ in a specimen with a diameter of $3.91 \mathrm{~cm}$ and a height of $8.0 \mathrm{~cm}$.

THF solutions are prepared to keep the fluid mass content at a level of $30 \%$, and the volume of fluid is about $37.5 \mathrm{ml}$ in the specimens. The geotechnical parameters such as the volume of water and THF before SCTH synthesis are given in Table 1.

The hydrate saturation is calculated by equation (1).

$S_{H}=\frac{V_{H}}{V_{p}}$

where $S_{H}, V_{H}$, and $V_{p}$ are the hydrate saturation, the volume of hydrate, and the volume of pores, respectively.

After filling with THF solution, the specimens are placed into the pressure chamber and kept at a temperature of $2{ }^{\circ} \mathrm{C}$ for 2 days to ensure the synthesis of SCTH. The effective porosity of the unsaturation soil after hydrate formations are $52.1 \%, 49.5 \%, 44.3 \%, 39.1 \%$, $33.9 \%, 28.6 \%$, respectively. Then the effective confining pressure is applied, an axial displacement rate is controlled at $0.9 \mathrm{~mm} / \mathrm{min}$, and the axial force and displacement as the stress and strain are recorded. The effective confining pressures are 2.5 $\mathrm{MPa}, 5 \mathrm{MPa}$,

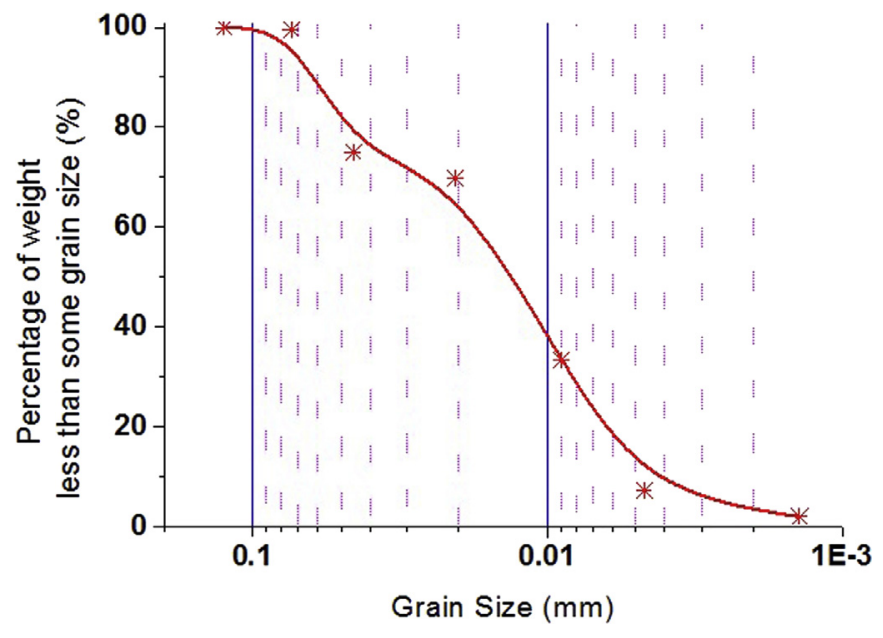

Figure 2. Grain size distribution.

Table 1

Geotechnical parameters.

\begin{tabular}{lllllll}
\hline$S_{\mathrm{h}} / \%$ & $G_{\mathrm{d}}$ & $\rho_{\mathrm{d}} / \mathrm{g} / \mathrm{cm}^{3}$ & $\varphi$ & $V_{w} / \mathrm{ml}$ & $V_{\mathrm{THF}} / \mathrm{ml}$ & $V_{\mathrm{H}} / \mathrm{ml}$ \\
\hline 0 & 2.7 & 1.3 & 0.52 & 0 & 37.5 & 0 \\
5 & 2.7 & 1.3 & 0.52 & 2.0 & 35.5 & 2.5 \\
15 & 2.7 & 1.3 & 0.52 & 6.0 & 31.5 & 7.5 \\
25 & 2.7 & 1.3 & 0.52 & 9.9 & 27.6 & 12.5 \\
35 & 2.7 & 1.3 & 0.52 & 13.9 & 23.6 & 17.5 \\
45 & 2.7 & 1.3 & 0.52 & 17.9 & 19.6 & 22.5 \\
\hline
\end{tabular}

Here $S_{\mathrm{h}}, G_{\mathrm{d}}, \rho_{\mathrm{d}}, \varphi, V_{w}, V_{\mathrm{THF}}$, and $V_{\mathrm{H}}$ represents THF hydrate saturation, soil specific weight, dry density, porosity, the volume of water, the volume of THF, and the volume of THF hydrate, respectively.

$8 \mathrm{MPa}$, respectively, and the temperature is $2^{\circ} \mathrm{C}$, which is similar to the existing condition of the hydrate in South China Sea (Shi et al., 2015).

\section{Test results}

Based on a series of tests, the stress-strain curves and Mohr circles are shown in Figures 3-8. Three specimens in a same degree of hydrate saturation and the three different effective confining pressures are tested according to the requirement of the Mohr

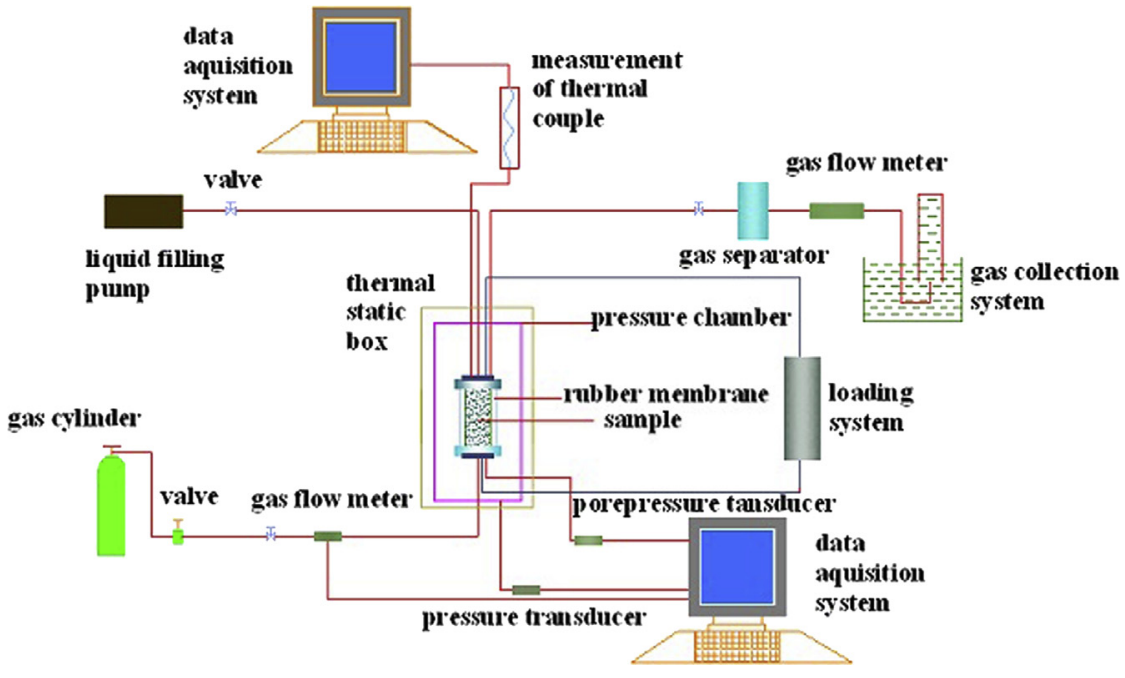

Figure 1. The integrated test apparatus for synthesis of hydrate sediment and tri-axial tests. 

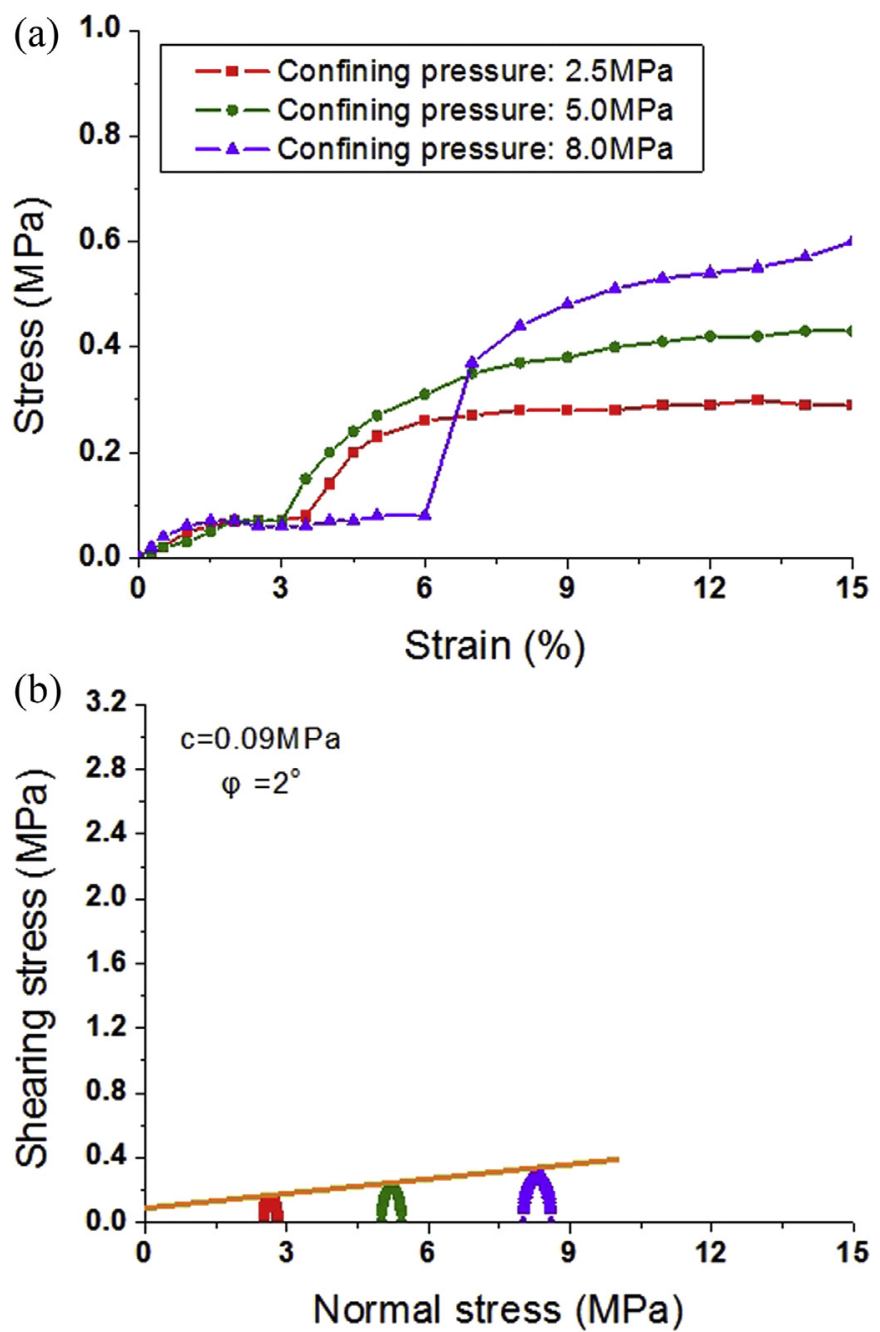

Figure 3. Stress-strain and Mohr circle curves $\left(S_{h}=0\right)$ (a) Stress-strain curves (b) Mohr circles.

circles. The deviatoric stress $\sigma_{1}-\sigma_{3}$ is regarded as shear strength. Here, $\sigma_{1}-\sigma_{3}$ represents the maximum deviatoric stress at the axial strain of $15 \%$, and $\sigma_{3}$ is the effective confining stress.

The stress-strain curves of the silty-clay without hydrate are shown in Figure 3a. The developments are all ductile and in two stages, the stress increases slowly with the increase of the strain in the first stage, while increases rapidly and then keeps constant in the second stage. The deviatoric stress $\sigma_{1}-\sigma_{3}$ reaches about $0.3 \mathrm{MPa}, 0.43 \mathrm{MPa}, 0.6 \mathrm{MPa}$ under the confining pressure of 2.5 MPa, 5.0 MPa, 8.0 MPa. The cohesion and internal friction angle are $0.09 \mathrm{MPa}$ and $2^{\circ}$, respectively (see in Fig. $3 \mathrm{~b}$ ).

The stress-strain curves of the silty-clay with the hydrate saturations of $5 \%, 15 \%, 25 \%, 35 \%, 45 \%$ are shown in Figures $4-8$, respectively. The developments are similar to that without hydrate. In the first stage of stress-strain curves, a little change occurs at different hydrate saturations of $0 \%, 5 \%, 15 \%, 25 \%, 35 \%, 45 \%$, while in the second stage, the stress increases rapidly when the strain reaches less than $6 \%$. The deviatoric stresses reach about $0.71 \mathrm{MPa}$, $1.06 \mathrm{MPa}$, and $1.24 \mathrm{MPa}$ at the hydrate saturation of $5 \%, 0.93 \mathrm{MPa}$, $1.19 \mathrm{MPa}$, and $1.41 \mathrm{MPa}$ at the hydrate saturation of $15 \%, 1.82 \mathrm{MPa}$, 2.04 MPa, and 2.42 MPa at the hydrate saturation of $25 \%, 1.92 \mathrm{MPa}$, $2.22 \mathrm{MPa}$, and $2.83 \mathrm{MPa}$ at the hydrate saturation of $35 \%, 2.15 \mathrm{MPa}$, $2.66 \mathrm{MPa}$, and $2.98 \mathrm{MPa}$ at the hydrate saturation of $45 \%$, corresponding to the confining pressures $2.5 \mathrm{MPa}, 5.0 \mathrm{MPa}$, and 8.0 MPa, respectively. The cohesion and internal friction angle are $0.26 \mathrm{MPa}$
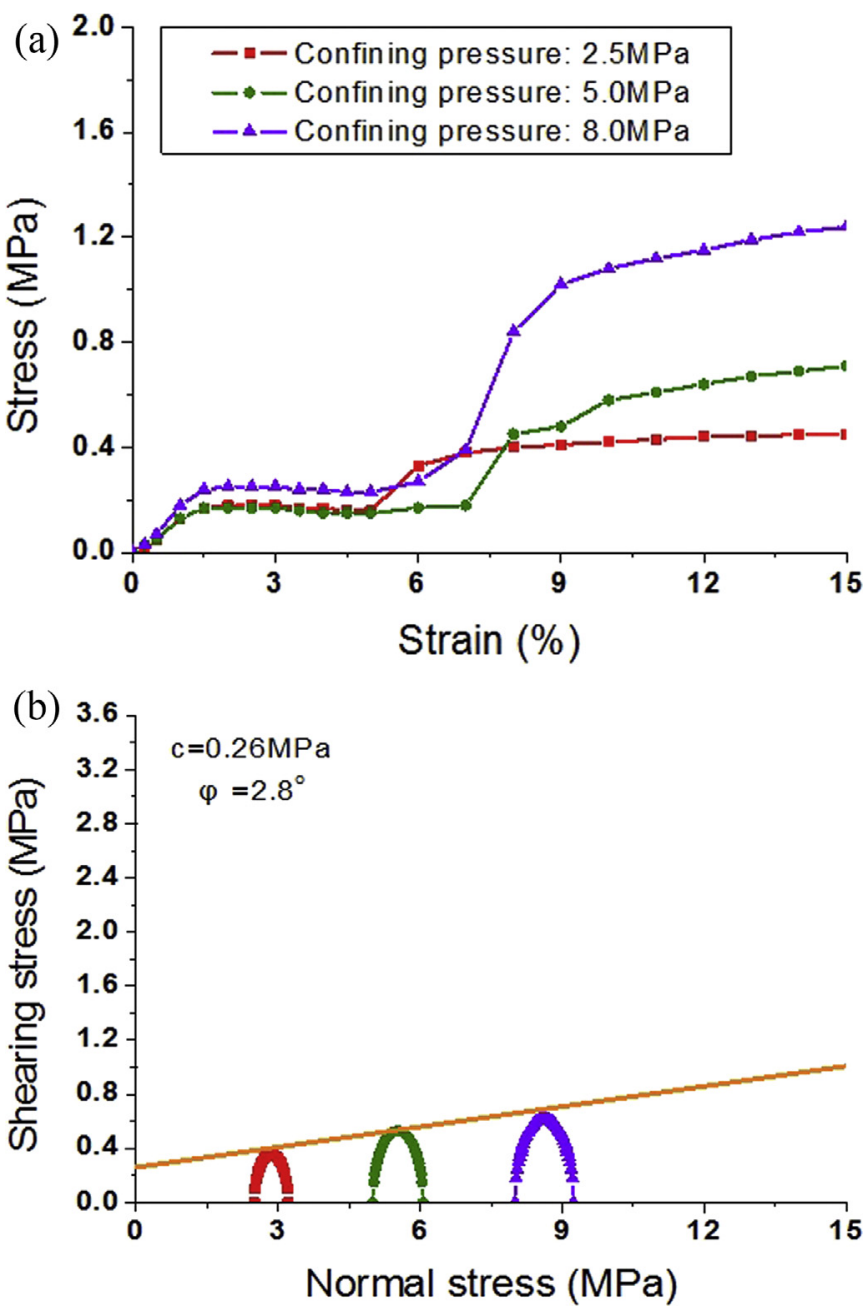

Figure 4. Stress-strain and Mohr circle curves $\left(S_{h}=5 \%\right.$ ) (a) Stress-strain curves (b) Mohr circles.

and $2.9^{\circ}, 0.35 \mathrm{MPa}$ and $2.9^{\circ}, 0.78 \mathrm{MPa}$ and $2.9^{\circ}, 0.82 \mathrm{MPa}$ and $3.2^{\circ}$, $0.97 \mathrm{MPa}$ and $3.4^{\circ}$, respectively.

The stress-strain curves at different degrees of hydrate saturation are presented in Figure 9. The general trend is that the second stages start at a smaller strain for a higher degree of hydrate saturation. The elasto-plastic deformations occur in the small stress and strain condition, the stress keeps constant when the stain achieves less than $6 \%$, then increases rapidly and strain hardening occurs. It is noted that the strain softening with an obvious strength peak is typical for gas hydrate-bearing sands (Winters et al., 2007). The preliminary physical explanations are that in the initial compression stage, the soils are compacted with constant pore fluid migration and soil consolidation, and the pore is compressed a little in the small stress and strain condition. Continued compression leads to more significant rotation, slide and rearrangement among the grains. Hence, the strain hardening occurs when the effective porosity exceeds a certain value and hydrate bearing effect is exerted.

The higher hydrate saturation and confining pressure lead to a larger stiffness and strength because a higher degree of hydrate saturation increases more hydrate connection and uniform cementation among the grains in the second stage. The hydrate and its micro occurrence dominate the development of the stress-strain curves and a higher confining pressure allows a less lateral deformation. Both the hydrate and the cementation among the grains bear the force. Hence the micro hydrate occurrence (from 

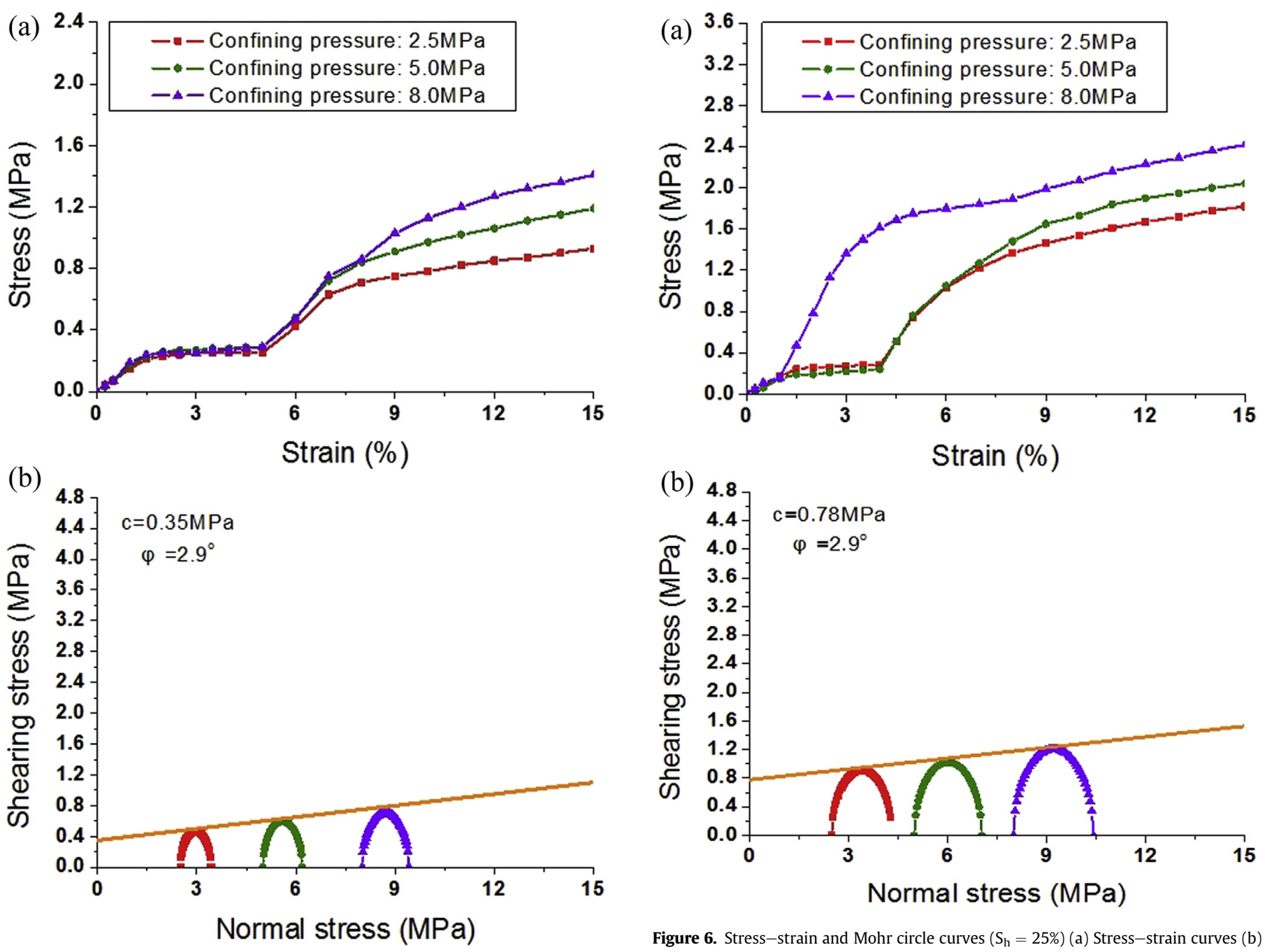

Figure 5. Stress-strain and Mohr circle curves $\left(S_{h}=15 \%\right)$ (a) Stress-strain curves (b) Mohr circles.

pore-filling to cementation) affects the macro strength and stiffness of hydrate bearing sediments (Lu et al., 2013).

The developments of the shear strength, cohesion, internal frictional angle and secant modulus of SCTH with the hydrate saturation and the confining pressure are shown in Figure 10. The shear strength increases linearly with the increase of hydrate saturation and confining pressure. The cohesion increases with the increase of hydrate saturation because the hydrate strengthens the cementation among the grains of the silty clay. The internal frictional angle changes a little around $3^{\circ}$ under the unsaturated and undrained condition because the bite force is small although the capacity of contact and adsorption among the grains is large. The secant modulus $\left(E_{t}=\left(\sigma_{1}-\sigma_{3}\right)_{\text {strain }}=7.5 \% / 7.5 \%\right)$ is selected to represent the stiffness of the soil material. The secant modulus increases a little with the increase of the hydrate saturation and the confining pressure, which can be explained that even at a low degree of hydrate saturation, the cementation among the grains occurs and dominates the stiffness of SCTH under the current synthesis method (Yun et al., 2007).

\subsection{Analysis of the shear strength of SCTH}

Due to the dependence of the shear strength on degrees of hydrate saturation, modified models are presented based on typical

Figure 6. Stress-strain and Mohr circle curves $\left(S_{h}=25 \%\right)$ (a) Stress-strain curves (b) Mohr circles.

models of the Drucker-Prager criterion, the Mohr-Coulomb criterion, and the Lade-Duncan criterion.

\section{(1) Analysis based on the Drucker-Prager criterion}

Based on the Drucker-Prager criterion, the effect of hydrate saturation $S_{\mathrm{h}}$ is considered, and the strength of SCTH is expressed as follows:

$\sqrt{J_{2}}=K_{f}\left(S_{h}\right)+\beta\left(S_{h}\right) \cdot I_{1}$

in which $J_{2}=1 / 6\left(\left(\sigma_{1}-\sigma_{2}\right)^{2}+\left(\sigma_{2}-\sigma_{3}\right)^{2}+\left(\sigma_{3}-\sigma_{1}\right)^{2}\right)$, $I_{1}=\sigma_{1}+\sigma_{2}+\sigma_{3}$, while $K_{f}\left(S_{h}\right)$ and $\beta\left(S_{h}\right)$ are the material parameters varying with the hydrate saturation.

In the tri-axial tests, the second principal stress equals to the third principal stress, i.e. $\sigma_{2}=\sigma_{3}$, substitute it into $J_{2}$ and $I_{1}$, Equation (2) is written as:

$\sigma_{1}-\sigma_{3}=\sqrt{3} K_{f}\left(S_{h}\right)+\sqrt{3} \beta\left(S_{h}\right) \cdot\left(\sigma_{1}+2 \sigma_{3}\right)$

Let $\sigma_{1}-\sigma_{3}$ (Here, $\sigma_{1}-\sigma_{3}$ is the deviatoric stress at the strain of $15 \%$ ) is the function of $S_{h}$ and $\sigma_{3}$, Equation (3) is rewritten as:

$\sigma_{1}-\sigma_{3}=A\left(S_{h}\right)+B\left(S_{h}\right) \cdot \sigma_{3}$ 

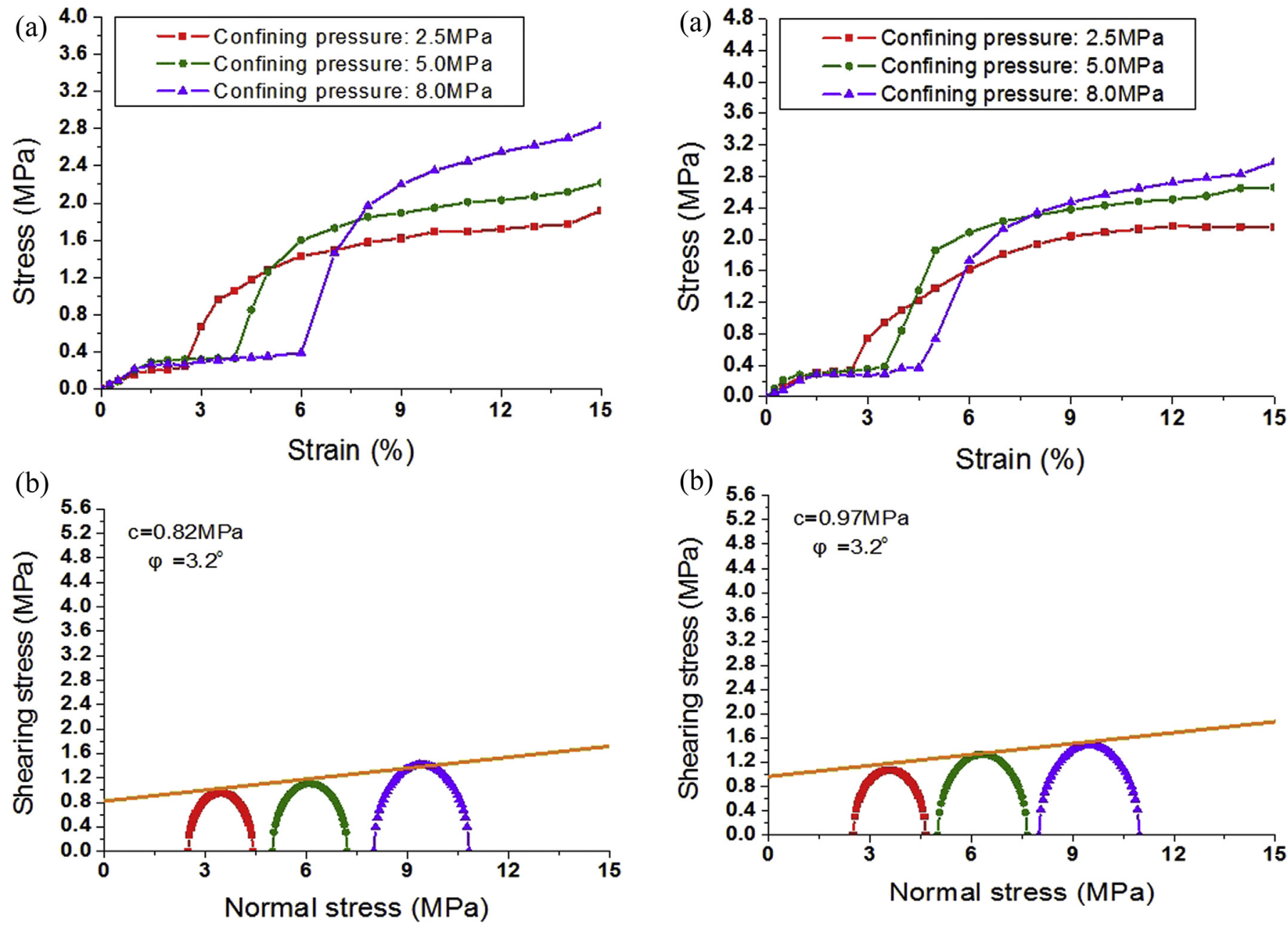

Figure 7. Stress-strain and Mohr circle curves $\left(S_{h}=35 \%\right)$ (a) Stress-strain curves (b) Mohr circles.

in which $A\left(S_{h}\right)=\frac{\sqrt{3} K_{f}\left(S_{h}\right)}{1-\sqrt{3} \beta\left(S_{h}\right)}, B\left(S_{h}\right)=\frac{3 \sqrt{3} \beta\left(S_{h}\right)}{1-\sqrt{3} \beta\left(S_{h}\right)}$.

Due to the increases of $\sigma_{1}-\sigma_{3}$ with $S_{h}$ and $\sigma_{3}$ are linear approximately, Equation (4) is simplified by the first order approximation as:

$\sigma_{1}-\sigma_{3}=\left(A^{\prime}(0) \cdot S_{h}+A(0)\right)+\left(B^{\prime}(0) \cdot S_{h}+B(0)\right) \cdot \sigma_{3}$

in which $A\left(S_{h}\right)=\frac{\sqrt{3} K_{f}\left(S_{h}\right)}{1-\sqrt{3} \beta\left(S_{h}\right)}, B\left(S_{h}\right)=\frac{3 \sqrt{3} \beta\left(S_{h}\right)}{1-\sqrt{3} \beta\left(S_{h}\right)}$,

$$
A^{\prime}(0)=\frac{\partial A\left(S_{h}=0\right)}{\partial S_{h}}, B^{\prime}(0)=\frac{\partial B\left(S_{h}=0\right)}{\partial S_{h}} .
$$

Then the above parameters can be obtained by fitting of the test data and using the least squares method. If $n$ groups of test results are presented, the shear strength can be written as a form of vector:

$\sigma_{1}-\sigma_{3}=Y=\left(\begin{array}{c}y_{1} \\ \vdots \\ y_{n}\end{array}\right)$

The matrix, consisted of the hydrate saturation and the effective confining pressure, is as follows:

Figure 8. Stress-strain and Mohr circle curves $\left(S_{h}=45 \%\right)$ (a) Stress-strain curves (b) Mohr circles.

$X=\left(\begin{array}{cccc}\left(S_{h}\right)_{0} & 1 & \left(S_{h} \cdot \sigma_{3}\right)_{0} & \left(\sigma_{3}\right)_{0} \\ \vdots & \vdots & \vdots & \vdots \\ \vdots & \vdots & \vdots & \vdots \\ \left(S_{h}\right)_{n} & 1 & \left(S_{h} \cdot \sigma_{3}\right)_{n} & \left(\sigma_{3}\right)_{n}\end{array}\right)$

The coefficient vector is solved as:

$\beta=\left(\begin{array}{l}A^{\prime}(0) \\ A(0) \\ B^{\prime}(0) \\ B(0)\end{array}\right)$

Here $Y=X \beta$.

According to the least square method, the vector of the coefficients can be expressed as:

$\beta=\left(X^{T} X\right)^{-1} X^{T} Y$

The solution can be obtained in a dimensionless form:

$$
\begin{aligned}
\frac{\sigma_{1}-\sigma_{3}}{\left(\sigma_{1}-\sigma_{3}\right)_{0}}= & \frac{A^{\prime}(0)}{\left(\sigma_{1}-\sigma_{3}\right)_{0}} \cdot S_{h}+\frac{A(0)}{\left(\sigma_{1}-\sigma_{3}\right)_{0}}+\left(B^{\prime}(0) \cdot S_{h}\right. \\
& +B(0)) \cdot \frac{\sigma_{3}}{\left(\sigma_{1}-\sigma_{3}\right)_{0}}
\end{aligned}
$$



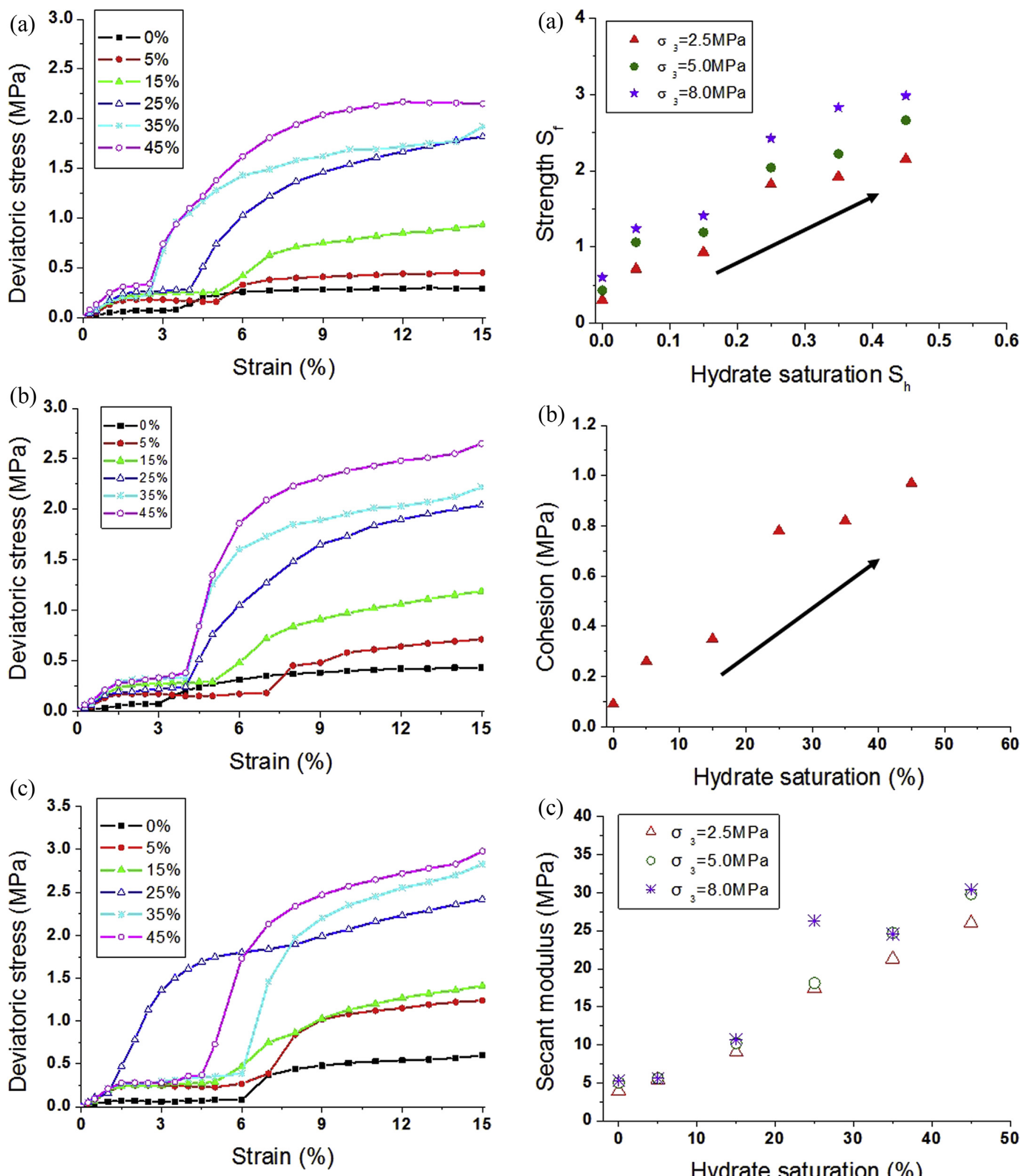

(b)
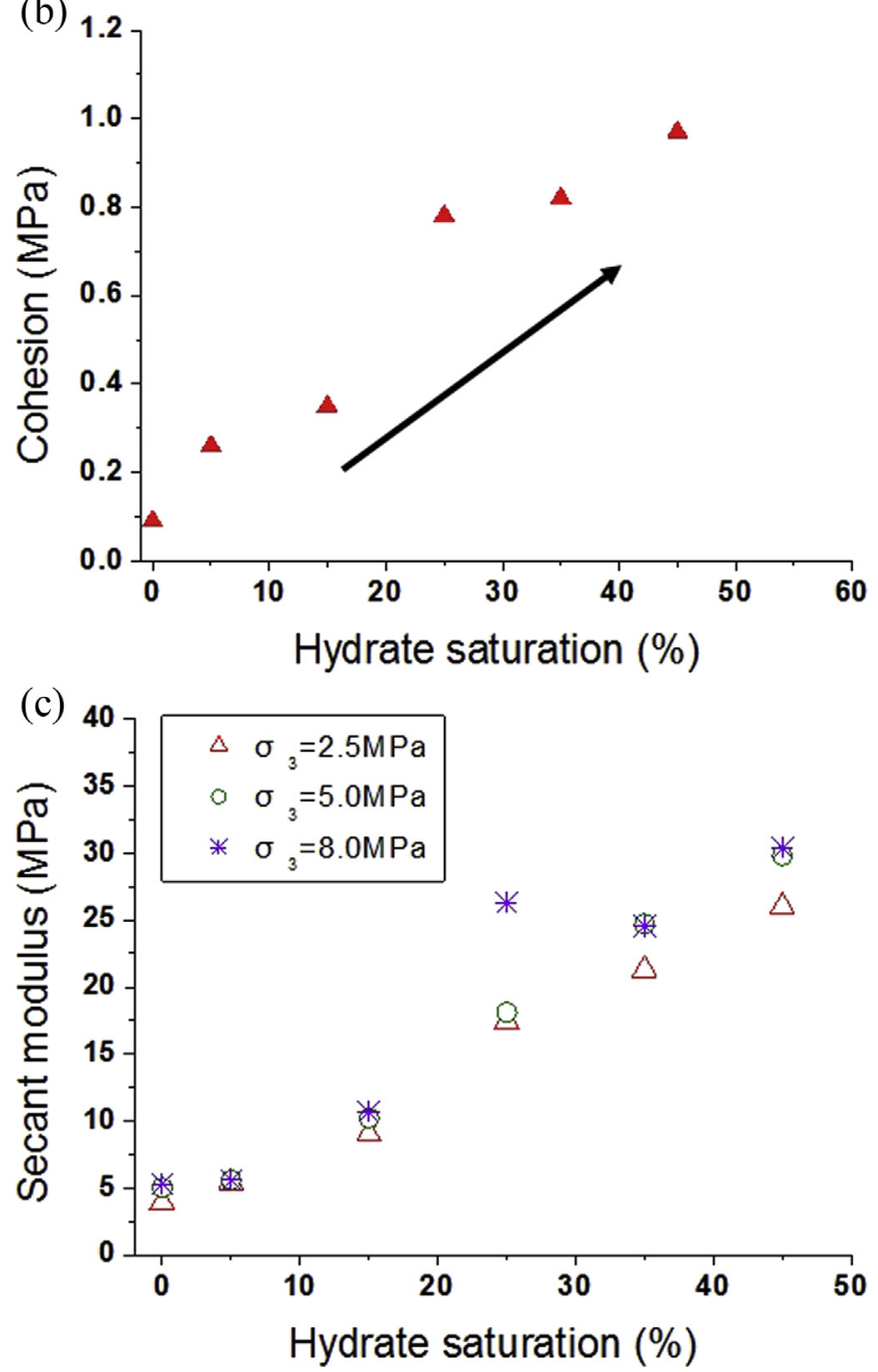

Figure 9. Developments of stress-strain curves at different hydrate saturation (a) Confining pressure $=2.5 \mathrm{MPa}$ (b) Confining pressure $=5.0 \mathrm{MPa}$ (c) Confining pressure $=8.0 \mathrm{MPa}$.

Figure 10. Strength, cohesion and modulus at different hydrate saturation $\left(S_{f}=\left(\sigma_{1}-\sigma_{3}\right)_{\text {strain }}=15 \%\right)$. 
in which $\begin{aligned} & \frac{A^{\prime}(0)}{\left(\sigma_{1}-\sigma_{3}\right)_{0}}=12.2, \frac{A(0)}{\left(\sigma_{1}-\sigma_{3}\right)_{0}}=0.93, \\ & B^{\prime}(0)=0.22, B(0)=0.065 .\end{aligned}$

The above parameters are fitted by the test data, and the correlation coefficient $R^{2}$ is 0.95 (see in Fig. 11). The Drucker-Prager criterion can describe the shear strength of SCTH well under the test condition. In Figure $11, S_{f} / S_{0}=\left(\sigma_{1}-\sigma_{3}\right)_{f} /\left(\sigma_{1}-\sigma_{3}\right)_{0},\left(\sigma_{1}-\sigma_{3}\right)_{f}$ is the deviatoric stress at the strain of $15 \%,\left(\sigma_{1}-\sigma_{3}\right)_{0}$ is the deviatoric stress at the strain of $15 \%$ without hydrate under the confining pressure of $2.5 \mathrm{MPa}$.

(2) Analysis based on the Mohr-Coulomb criterion

According to the Mohr-Columb criterion, the deviatoric stress depends on the effective confining pressure, internal friction angle and cohesion:

$\sigma_{1}-\sigma_{3}=\frac{2 \sin \phi\left(S_{h}\right)}{1-\sin \phi\left(S_{h}\right)} \cdot \sigma_{3}+\frac{2 \cos \phi\left(S_{h}\right)}{1-\sin \phi\left(S_{h}\right)} \cdot c\left(S_{h}\right)$

From the test data, the internal friction angle changes a little with hydrate saturation, while the cohesion increases with the increase of hydrate saturation. Here the linear relationship between the cohesion and the hydrate saturation is assumed, then equation can be expressed as:

$\sigma_{1}-\sigma_{3}=F_{1} \cdot \sigma_{3}+F_{2} \cdot\left(c(0)+c^{\prime}(0) \cdot S_{h}\right)$

in which $F_{1}=\frac{2 \sin \phi_{0}}{1-\sin \phi_{0}}, F_{2}=\frac{2 \cos \phi_{0}}{1-\sin \phi_{0}}$.

if $n$ groups of test results are given, the strength can be written as a form of vector:

$\sigma_{1}-\sigma_{3}=Y=\left(\begin{array}{c}y_{1} \\ \vdots \\ y_{n}\end{array}\right)$

The matrix, consisted of the hydrate saturation and the confining pressure, is as follows:

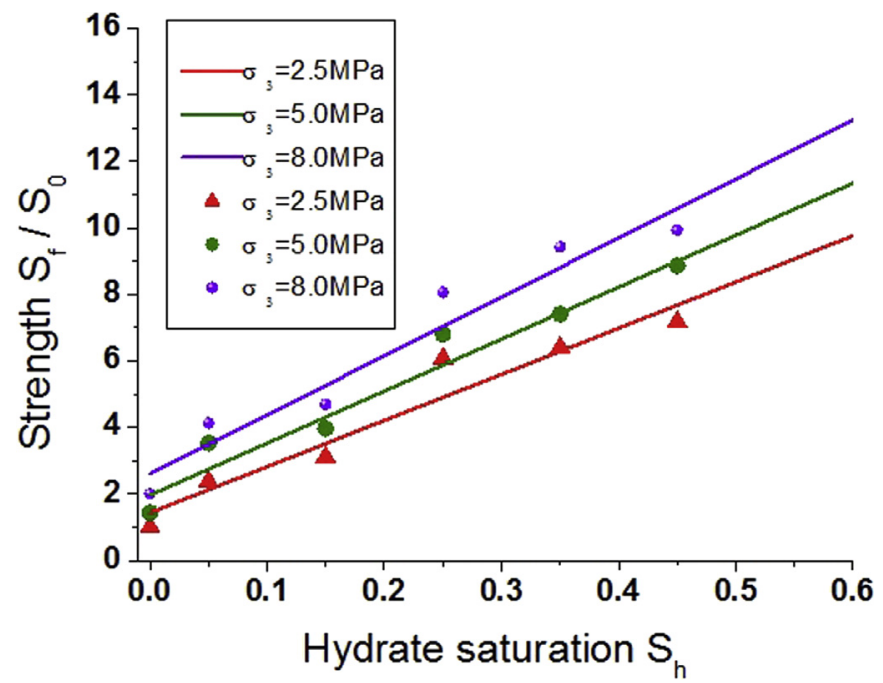

Figure 11. Comparison of the shear strength based on the Drucker-Prager criterion.
$X=\left(\begin{array}{ccc}\left(\sigma_{3}\right)_{0} & 1 & \left(S_{h}\right)_{0} \\ \vdots & \vdots & \vdots \\ \left(\sigma_{3}\right)_{n} & 1 & \left(S_{h}\right)_{n}\end{array}\right)$

The coefficient vector can be solved:

$\beta=\left(\begin{array}{c}E \\ F \cdot c(0) \\ F \cdot c^{\prime}(0)\end{array}\right)$

Here $Y=X \beta$.

According to the least square method, the solution of vector of the coefficients can be achieved as follows:

$\beta=\left(X^{T} X\right)^{-1} X^{T} Y$

Then the solution $E=0.1, F \cdot c(0)=0.044 \mathrm{MPa}, F \cdot c^{\prime}(0)=4.8 \mathrm{MPa}$ is obtained, and the correlation coefficient $R^{2}$ is 0.90 as in Figure 12.

(3) Analysis based on the Lade-Duncan criterion

According the Lade-Duncan criterion (Lade and Duncan, 1975), the relationship of the shear strength and the hydrate saturation can be expressed as follows:

$I_{1}^{3} / I_{3}=K_{L D}\left(S_{h}\right)$

in which $I_{1}=\sigma_{1}+\sigma_{2}+\sigma_{3}, I_{3}=\sigma_{1} \cdot \sigma_{2} \cdot \sigma_{3}$, while $K_{L D}\left(S_{h}\right)$ is the material parameters varying with hydrate saturation.

In the tri-axial tests, $\sigma_{2}=\sigma_{3}$, then Equation (17) can be written as:

$\frac{\left(\sigma_{1}+2 \sigma_{3}\right)^{3}}{\sigma_{1} \cdot \sigma_{3}^{2}}=\frac{\left(\frac{\sigma_{1}}{\sigma_{3}}+2\right)^{3}}{\frac{\sigma_{1}}{\sigma_{3}}}=K_{L D}\left(S_{h}\right)$

Take the logarithm of Equation (18):

$3 \lg \left(\frac{\sigma_{1}}{\sigma_{3}}+2\right)-\lg \frac{\sigma_{1}}{\sigma_{3}}=\lg K_{L D}\left(S_{h}\right)$

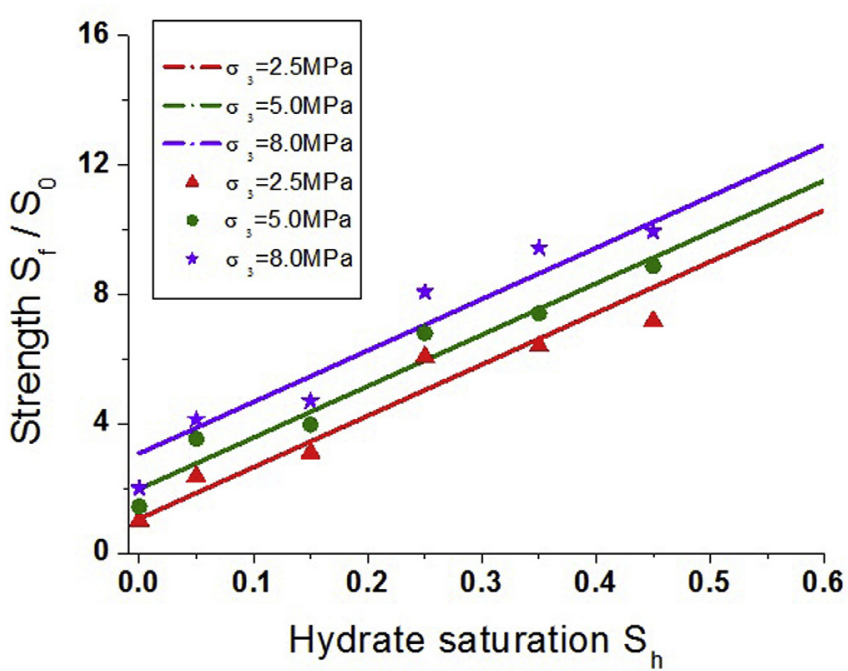

Figure 12. Comparison of the shear strength based on the Mohr-Coulomb criterion. 
In Equation (19), the relationship between $\lg \left(\sigma_{1} / \sigma_{3}+2\right)$ and $\lg \sigma_{1} / \sigma_{3}$ is linear, while this is not in agreement with the test results. The Lade-Duncan model applies to cohesionless soils considering elastoplastic deformation, non-associated flow rule and plastic work hardening law.

Under the plane strain condition, if the yield line of the Drucker-Prager criterion is internally tangent to that of the Mohr-Coulomb criterion in the deviatoric plane, Equation (4) and Equation (11) are equivalent (Zheng et al., 2002). In the first order approximation, the Drucker-Prager criterion and the Mohr-Coulomb criterion provide a good empirical relationship between the shear strength, the hydrate saturation, and the effective confining pressure, while the Lade-Duncan criterion is invalid for SCTH.

\subsection{A model for the analysis of modulus of SCTH}

Silty clay containing THF hydrate is a multi-phase composite material consisted of soil skeleton, hydrate and pore fluid. Due to the unsaturation status of the soil and a small fluid pressure, the effect of pore fluid on the modulus of SCTH is neglected and the soil skeleton and pores are regarded as a whole. The models of modulus based on the mixed law for composite materials are modified and applied here (Hill, 1965).

Under the equivalent strain condition, the total stress equals the sum of the stress of each phase in SCTH. Then one dimension elastic deformation is applied, the modulus of composite materials can be expressed as:

$E_{s}=v_{a} E_{a}+v_{b} E_{b}$

Under the equivalent stress condition, the total deformation equals the sum of the deformation of each phase in SCTH. Then one dimension elastic deformation is applied, the modulus of composite materials can be expressed as:

$E_{p}=\left(\frac{v_{a}}{E_{a}}+\frac{v_{b}}{E_{b}}\right)^{-1}$

in which $v, E$ represent the volume fraction and modulus, $a, b$ represent soil skeleton and hydrate phase, respectively.

If SCTH is assumed to be isotropic and uniform, the geometric average $E_{G A}=\sqrt{E_{S} \cdot E_{p}}$ and the harmonic average $E_{H A}=2 E_{s} \cdot E_{p} /$ $E_{S}+E_{p}$ can be regarded as two bounds for the modulus of SCTH. Compared with the simulated results, the test secant modulus of SCTH is contained in the two bounds and close to that of the harmonic average as in Figure 13.

\section{Conclusions}

The mechanical properties of SCTH are obtained by the integrated test apparatus for synthesis of hydrate sediment and triaxial tests. The effects of the hydrate saturation and the effective confining pressure on the shear strength and the secant modulus are investigated. The shear strength is analyzed based on the Drucker-Prager criterion, the Mohr-Coulomb criterion and the Lade-Duncan criterion, while the secant modulus is analyzed based on the mixed law for composite materials.

The conclusions can be drawn as follows:

The stress-strain curves show a typical ductile behavior. The pore compression dominates the initial stress-strain development for the porous unsaturated silty clay, and then strain hardening occurs.

The shear strength increases linearly with the increase of hydrate saturation and effective confining pressure. The cohesion

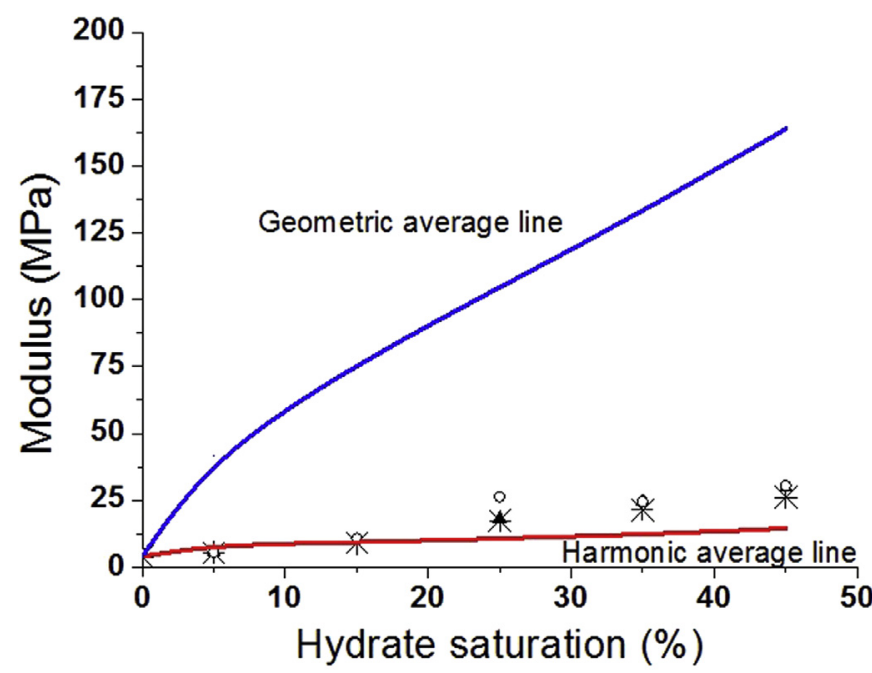

Figure 13. Comparison of the modulus based on the mixed law for composite materials.

increases with the increase of hydrate saturation while the internal frictional angle changes a little.

The shear strength is described well by the Drucker-Prager criterion and the Mohr-Coulomb criterion, while the Lade-Duncan criterion is invalid for SCTH. The secant modulus is close to the harmonic average of the modulus of soil skeleton and hydrate in SCTH.

This work is expected to provide a simple and practical reference for the evaluation of soil deformation and stratum instability in the hydrate exploitation of South China Sea.

\section{Acknowledgements}

This study is supported by the National Natural Science Foundation of China (No. 41376078, No. 51239010) and the China Geological Survey project (No. GZH201100311). Many thanks to the reviewers and professor Baiyi Wang for the revisions of English expressions.

\section{References}

Birchwood, R., Singh, R., Mese, A., 2008. Estimating the in situ mechanical properties of sediments containing gas hydrates. In: Proceedings of the 6th International Conference on Gas Gydrates (ICGH 2008). Vancouver, British Columbia.

Clayton, C.R.I., Priest, J.A., Best, A.I., 2005. The effects of disseminated methane hydrate on the dynamic stiffness and damping of a sand. Geotechnique 55 (6), 423-434.

ConocoPhillips, July 31, 2012. ConocoPhillips Gas Hydrate Production Test. Oil \& Natural Gas Technology, Progress report first half 2012. Office of Fossil Energy, Anchorage, USA

Dai, S., Santamarina, J.C., Waite, W.F., Kneafsey, T.J., 2012. Hydrate morphology: physical properties of sands with patchy hydrate saturation. J. Geophys. Res. 117, B11205. http://dx.doi.org/10.1029/2012JB009667.

Hill, R., 1965. A self-consistent mechanics of composite materials. J. Mech. Phys. Solids 13 (4), 213-222.

Hyodo, M., Nakata, Y., Yoshimoto, N., et al., 2007. Shear behaviour of methane hydrate-bearing sand. In: Proc. 17th Int. Offshore and Polar Engrg. Conf, pp. 1326-1333. Lisbon, Portugal.

Hyodo, M., Li, Y.H. Yoneda, J., et al., 2014. Effects of dissociation on the shear strength and deformation behavior of methane hydrate-bearing sediments. Mar. Pet. Geol. 51, 52-62.

Koh, C.A., 2002. Towards a fundamental understanding of natural gas hydrates. Chem. Soc. Rev. 31, 157.

Kvenvolden, K.A., Lorenson, T.D., 2001. The global occurrence of natural gas hydrate. Geophys. Monogr. 124, 3-18.

Lade, P.V., Duncan, J.M., 1975. Elastoplastic stress-strain theory for cohesionless soil. J. Geotech. Eng. Div. 101 (10), 1037-1053.

Lu, X.B., Zhang, X.H., Wang, S.Y., 2013. Advances in study of mechanical properties of gas hydrate bearing sediments. Open Ocean Eng. J. 6, 26-40. 
Li, Y.H., Song, Y.C., Liu, W., et al., 2012. Analysis of mechanical properties and strength criteria of methane hydrate-bearing sediments. Int. J. Offshore Polar Eng. 22 (4), 290-296.

Masui, A., Haneda, H., Ogata, Y., Aoki, K., 2007. Mechanical properties of sandy sediment containing marine gas hydrates in deep sea offshore Japan. In: Proc. 17th Int. Offshore and Polar Eng. Conf., Ocean Mining Symposium, Lisbon, Portugal, pp. 53-56.

Miyazaki, K., Masui, A., Haneda, H., et al., 2008. Variable-compliance-type constitutive model for methane hydrate bearing sediment. In: Proceedings of the 6 th International Conference on Gas Hydrates ( ICGH 2008). Vancouver, British Columbia.

Miyazaki, K., Masui, A., Sakamoto, Y., Aoki, K., Tenma, N., Yamaguchi, T., 2011a. Triaxial compressive properties of artificial methane-hydrate-bearing-sediment. J. Geophys. Res. 116, B06102. http://dx.doi.org/10.1029/2010JB008049.

Miyazaki, K., Aoki, K., Tenma, N., 2011b. A nonlinear elastic constitutive model for artificial methane-hydrate-bearing sediment. In: Proceedings of the 7th International Conference on Gas Hydrates ( ICGH 2011). Edinburgh, Scotland, United Kingdom.

Numasawa, M., Yamamoto, K., Yasuda, M., et al., July 6-10, 2008. Objectives and operation overview of the 2007 JOGMEC/NRCAN/AURORA Mallik 2L-38 gas hydrate production test. In: Proceedings of the 6th International Conference on Gas Hydrates, Vancouver, British Columbia, CANADA.

Shi, Y.H., Zhang, X.H., Lu, X.B., 2015. Experimental study on the static mechanica properties of hydrate-bearing silty-clay in the South China Sea. Chinese J. Theor: Appl. Mech. 47 (3), 521-528.
Uchida, S., Soga, K., Yamamoto, K., 2012. Critical state soil constitutive model for methane hydrate soil. J. Geophys. Res. 117, B03209. http://dx.doi.org/10.1029/ 2011JB008661.

Wei, H.Z., Yan, R.T., Chen, P., Tian, H.H., Wu, E.L., Wei, C.F., 2011. Deformation and failure behavior of carbon dioxide hydrate-bearing sands with different hydrate contents under triaxial shear tests. Rock Soil Mech. 32, 198-203.

Winters, W.J., Pecher, I.A., Waite, W.F., Mason, D.H., 2004. Physical properties and rock physics models of sediment containing natural and laboratory-formed methane gas hydrate. Am. Mineral. 89, 1221-1227.

Winters, W.J., Waite, W.F., Mason, D.H., et al., 2007. Methane gas hydrate effect on sediment acoustic and strength properties. J. Pet. Sci. Eng. 56, 127-135.

Yun, T.S., Santamarina, J.C., Rupple, C., 2007. Mechanical properties of sand, silt and clay containing tetrahydrofuran hydrate. J. Geophys. Res. 112, B04106. http:// dx.doi.org/10.1029/2006JB004484.

Yu, F., Song, Y.C., Liu, W.G., Li, Y.H., Lam, W.H., 2011. Analyses of stress strain behavior and constitutive model of artificial methane hydrate. J. Pet. Sci. Eng. 77, 183-188.

Zheng, Y.R., Shen, Z.J., Gong, X.N., 2002. Principle of Plastic Mechanics for Rock and Soil. China Architecture and Building Press, Beijing (in Chinese).

Zhang, X.H., Lu, X.B., Zhang, L.M., Wang, S.Y., Li, Q.P., 2012. Experimental study on mechanical properties of methane-hydrate-bearing sediments. Acta Mech. Sin. 28 (5), 1356-1366. 